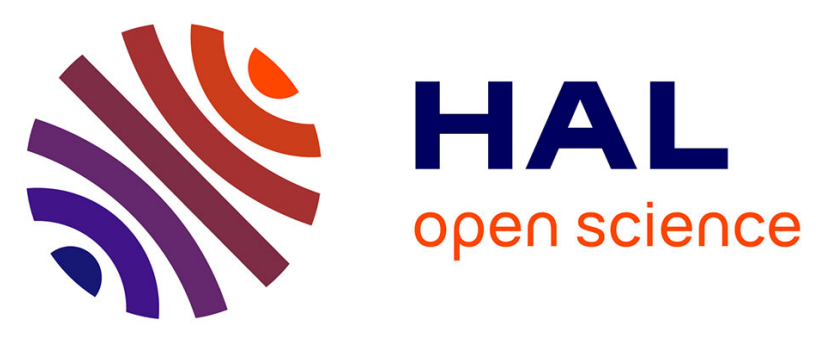

\title{
Postnatal overfeeding in rats leads to moderate overweight and to cardiometabolic and oxidative alterations in adulthood
}

Ahmed Habbout, Stephanie Delemasure, Françoise Goirand, Jean-Claude

Guilland, Franck Chabod, Mourad Sediki, Luc Rochette, Catherine Vergely

\section{To cite this version:}

Ahmed Habbout, Stephanie Delemasure, Françoise Goirand, Jean-Claude Guilland, Franck Chabod, et al.. Postnatal overfeeding in rats leads to moderate overweight and to cardiometabolic and oxidative alterations in adulthood. Biochimie, 2012, 94 (1), pp.117-124. 10.1016/j.biochi.2011.09.023 . hal03434326

\section{HAL Id: hal-03434326 \\ https://u-bourgogne.hal.science/hal-03434326}

Submitted on 18 Nov 2021

HAL is a multi-disciplinary open access archive for the deposit and dissemination of scientific research documents, whether they are published or not. The documents may come from teaching and research institutions in France or abroad, or from public or private research centers.
L'archive ouverte pluridisciplinaire HAL, est destinée au dépôt et à la diffusion de documents scientifiques de niveau recherche, publiés ou non, émanant des établissements d'enseignement et de recherche français ou étrangers, des laboratoires publics ou privés. 


\title{
Postnatal overfeeding in rats leads to moderate overweight and to
}

\section{cardiometabolic and oxidative alterations in adulthood}

\author{
Ahmed Habbout ${ }^{\text {a }}$, Stephanie Delemasure ${ }^{\text {a }}$, Françoise Goirand ${ }^{\text {a }}$, Jean-Claude Guilland \\ ${ }^{\text {a }}$, Franck Chabod ${ }^{\text {a }}$, Mourad Sediki ${ }^{\text {a }}$, Luc Rochette ${ }^{\text {a }}$, Catherine Vergely *a \\ ${ }^{a}$ Laboratoire de Physiopathologie et Pharmacologie Cardiovasculaires Expérimentales \\ (EA2979), Facultés de Médecine et Pharmacie, IFR SANTE-STIC, Université de Bourgogne,
} Dijon, France

* Corresponding author: Catherine VERGELY, LPPCE, Université de Bourgogne, Facultés de Médecine et de Pharmacie, 7 boulevard Jeanne d'Arc, 21000 Dijon, France. Phone: +33 3803934 60 ; Fax: +33 380393293 ; Email: cvergely@u-bourgogne.fr

Running title: Postnatal overfeeding, heart, oxidative stress

Conflict of interest statement: The authors declare to have no personal, financial or other relationships with other people or organizations within 3 years of beginning the work submitted that could inappropriately influence, or be perceived to influence, the work submitted.

Funding source statement: This work was supported by grants from the French Ministry of Research and from the Regional Council of Burgundy.

Abbreviations: Ach, acetylcholine; ANOVA, analysis of variance; AU, arbitrary units; BMI, body mass index; $\mathrm{BK}$, bradykinin; $+\mathrm{dP} / \mathrm{dt}$, left ventricular maximal pressure development; $-\mathrm{dP} / \mathrm{dt}$, left ventricular minimal pressure development; HR, heart rate; IU, international units; L, Langendorff mode; LDH, lactate dehydrogenase; LVDP, left ventricular developed pressure; LVEDP, left ventricular end-diastolic pressure; LVESP, left ventricular end-systolic pressure; MMP-2, matrix metallo-proteinase-2; NF, normal-fed; OF, overfeeding ; SOD, superoxide dismutase; RLU, relative light units; $\mathrm{ROOH}$, hydroperoxides; SNP, sodium nitroprussiate; W, working mode 


\section{Abstract}

In contrast to the masses of data on obesity, few data are available concerning the cardiometabolic and oxidative consequences of moderate overweight. The model of postnataloverfeeding (OF) induces an increase in body weight at weaning that remains during adult life. Litters of Wistar rats were either maintained at 12 (normal-fed group, NF), or reduced to 3 at birth in order to induce OF. At 6 months of age, metabolic parameters, circulating oxidative stress and aortic and coronary vasoreactivity were assessed. Cardiac susceptibility to ischemiareperfusion injury was also evaluated ex vivo as were markers of cardiac remodeling. OF led to an increase in body weight at weaning $(+50 \%)$; the increase in body weight persisted throughout adult life, but was less marked $(+10 \%)$. Significant increases in plasma levels of fasting glucose, insulin and leptin were observed in OF. An increase in both plasma hydroperoxides and cardiac superoxide dismutase activity and a decrease in plasma ascorbate were observed in OF rats. Vasoreactivity was not modified, but ex vivo, after 30 minutes of ischemia, isolated hearts from OF rats showed lower recovery of coronary flow along with a greater release of LDH. Studies on heart tissues showed an increase in collagen content, and increased expression and activity of MMP-2.

Our findings show that moderate overweight in adult rats, induced by postnatal overfeeding, leads to both metabolic and oxidative disturbances as well as a higher susceptibility to cardiac injury after ischemia ex vivo, which may be explained, at least in part, by ventricular remodeling.

1. Keywords: Postnatal overfeeding, Oxidative stress, Heart, Ischemia, Rats 


\section{Introduction}

Metabolic syndrome, a cluster of several abnormalities including the build-up of abdominal fat, glucose imbalance, dyslipidemia and increased blood pressure, is a major risk factor for the development of cardiovascular diseases. We have already shown that the prevalence of metabolic syndrome in an unselected population of patients undergoing myocardial infarction was high, and that an elevated body mass index (BMI) and waist circumference were associated with a higher risk of heart failure and death at one year [1, 2]. Clinical and experimental evidence shows that the nutritional environment during the peri-natal period plays an important role in regulating both metabolic and hormonal tendencies in adulthood, and that nutrition in early life has an impact on the subsequent risk of overweight and hypertension [3]. In the past few years, certain authors showed that inducing early post-natal over-nutrition in rats, just by reducing litter sizes, led to profound changes in body weight at weaning (nearly $30 \%$ increase); the increase in body weight persisted with maturation, but was less marked (10-15\% increase) [4-6]. Certain authors reported increases in fasting glucose, plasma insulin, triglycerides and leptin levels at weaning and later [7-9], while others observed a discrete increase in blood pressure [4, 10]. Thus, a cluster of symptoms characteristic of metabolic syndrome occurred in neonatally overfed rats. However, few indepth explorations of the cardiovascular consequences of this moderate overweight have been reported.

While much work has been done on the cardiovascular consequences of high-fat diets or on genetically obese experimental animals, little research has been reported on the cardiovascular consequences of moderate overweight, and postnatal overfeeding might provide a good experimental model for studying classical risk factors for cardiovascular disease associated with early-induced permanent overweigh. In addition, several experimental studies have 
demonstrated that in overweight or obese individuals, an increase in energy metabolism increases the production of reactive oxygen species production [11]. As a consequence, this general increase in oxidative stress is able to initiate or reinforce various metabolic or functional disorders which in turn accentuate pathologies such as hypertension, atherosclerosis or heart failure [12].

Therefore, the aim of our work was to evaluate the metabolic, oxidative and cardiovascular consequences moderate overweight induced by post-natal over-nutrition in rats.

\section{Materials and Methods}

\subsection{Animals and diets}

Adult female Wistar rats (Charles River, L'Arbresle, France) were caged with male rats at a proportion of 2:1, then housed in individual cages and given water and standard pellet diet $a d$ libitum (A03, SAFE Diets Augy, France), during pregnancy and lactation. To induce early postnatal overfeeding, the litter size was reduced. Litters were either maintained at 12 malepups (normal-fed, NF group), or reduced to 3 male-pups in order to induce postnatal overfeeding (over-fed, OF group). After weaning (day 24), rats of both groups had free access to standard diet (A03, SAFE Diets Augy, France) and water. The composition of the standard diet was $69 \%$ of cereals, $20 \%$ of vegetable proteins (soya), $6 \%$ of animal proteins (fish) and $5 \%$ of vitamins and minerals mixture, corresponding to $52 \%$ of carbohydrates, $21 \%$ of protein, $5 \%$ fat, and $4 \%$ fibers as macronutrient intake. Throughout life, body weight and food intake were measured weekly then monthly. The local Ethics Committee approved the 
experimental protocol (see paragraph 5), and the investigators complied with authorization 3408 of the French government. The investigation conforms to the Directive 2010/63/EU of the European Parliament.

\subsection{Plasma and tissue sampling}

At 6-months old, and after 12-hours fasting, rats from NF and OF groups were anesthetized with sodium thiopental (60 mg/kg, i.p.), and heparin was intravenously injected (500 UI/kg). Blood was collected from the abdominal aorta, and immediately centrifuged at $4{ }^{\circ} \mathrm{C}$ in order to separate the plasma, and samples were stored at $-80^{\circ} \mathrm{C}$ until subsequent measurements. Thoracic aortas and hearts were quickly harvested to determine cardiovascular function and oxidative stress levels in tissues (see later).

\subsection{Biochemical measurements}

Plasma glucose concentration was determined by a glucometer, and plasma insulin, leptin and adiponectin were determined by EIA using specific commercial kits (Gentaur, Paris, France). Cholesterol was assayed on a Victor 1420 Multilabel Counter (Wallac-Perkin Elmer Life Sciences, Courtaboeuf, France) using a commercially available kit (Diasys, Condom, France). 


\subsection{Oxidative stress measurements}

2.4.1 Plasma oxidative stress level

Oxidative stress was determined in $10 \mu \mathrm{L}$ of plasma by the free oxygen radical test (F.O.R.T, FORM-PLUS-3000, Optimabio, Ollioules, France). The color intensity correlates directly with the amount of hydroperoxide and, consequently, with the oxidative stress level [13].

Vitamin C content was assessed in $100 \mu \mathrm{L}$ of plasma, stabilized by the addition of $200 \mu \mathrm{L}$ of metaphosphoric acid (5\%) and measured by high-performance liquid chromatography coupled with fluorimetric detection $(\lambda \mathrm{ex}=360 \mathrm{~nm}$ and $\lambda \mathrm{em}=440 \mathrm{~nm})[14]$.

\subsubsection{Antioxidant enzyme activity in the heart}

After an ex vivo ischemia/reperfusion protocol, the hearts were frozen in liquid nitrogen and stored at $-80^{\circ} \mathrm{C}$ until the subsequent measurement of ventricular antioxidant enzyme activity.

Superoxide dismutase (SOD) general activity was measured in heart samples using a method described previously [15]. Catalase activity in the heart was measured using a modified method [16] derived from Aebi and Clairbone [17]. All cardiac enzyme activities were related to protein content determined by the Lowry method.

\subsubsection{NADPH oxidase activity in the heart and aorta}

The capacity of cardiac or vascular tissue to produce $\mathrm{O}_{2}{ }^{--}$in an $\mathrm{NAD}(\mathrm{P}) \mathrm{H}$-dependent way was assessed using an LB9507 luminometer (Berthold Systems, Thoiry, France), by the measurement of superoxide-enhanced lucigenin $(5 \mu \mathrm{M})$ chemiluminescence, in the presence or absence of $\mathrm{NAD}(\mathrm{P}) \mathrm{H}(100 \mu \mathrm{mol} / \mathrm{L})$ as described previously [18]. The results are expressed 
in relative light units (RLU) per mg of protein for the heart and in milligrams of dry tissue for the aorta.

\subsection{Susceptibility to ex vivo Ischemia/Reperfusion (I/R) injury}

2.5.1. Preparation of isolated working hearts

After the rats had been anesthetized with sodium thiopental $(60 \mathrm{mg} / \mathrm{kg}$, i.p. $)$ and heparin injection (see previously), the hearts were excised and placed in a cold $\left(4^{\circ} \mathrm{C}\right)$ perfusion buffer bath until contractions ceased. The hearts were cannulated in the Langendorff mode, and perfused at $37^{\circ} \mathrm{C}$ with oxygenated $\left(\mathrm{O}_{2} / \mathrm{CO}_{2}, 95 \% / 5 \%\right)$, Krebs-Henseleit (pH 7.40) solution containing (in mmol/L) NaCl, 118; $\mathrm{NaHCO}_{3}, 25 ; \mathrm{KCl}, 4.7 ; \mathrm{MgSO}_{4}, 1.2 ; \mathrm{KH}_{2} \mathrm{PO}_{4}, 1.2 ; \mathrm{CaCl}_{2}$, 3; glucose, 5.5; at a constant hydrostatic perfusion pressure $(55 \mathrm{mmHg})$. A catheter was inserted into the left ventricle and connected to a pressure transducer to measure heart rate (HR) and left ventricular pressures: left ventricular end-diastolic pressure (LVEDP), left ventricular end-systolic pressure (LVESP), left ventricular developed pressure (LVDP=LVESP-LVEDP), and the first derivative of LVDP, left ventricular maximal pressure development $(+\mathrm{dP} / \mathrm{dt})$ and relaxation $(-\mathrm{dP} / \mathrm{dt})$. The above cardiac parameters were calculated using software (A.D.E., Technolog21, Dijon, France) developed in collaboration with computer and electronics scientists. Then, an atrial cannula was inserted through the orifice of the pulmonary veins in order to perfuse the right atrium with a constant preload pressure of 15 $\mathrm{mmHg}$ in order to switch to the working mode. In this condition, the fluid was ejected by left ventricular contraction through the aortic root against a stable post-load pressure of 55 mmHg. Throughout each experiment, the coronary flow, aortic and cardiac output (calculated as a total of coronary and aortic output) were recorded. 


\subsubsection{Ischemia/Reperfusion (I/R) protocol}

The isolated hearts were perfused in the working (W) mode for $12 \mathrm{~min}$, and then the perfusion was turned off in order to induce $30 \mathrm{~min}$ of total global normothermic ischemia, followed by reperfusion in the Langendorff $(\mathrm{L})$ mode for $12 \mathrm{~min}$ and for $30 \mathrm{~min}$ in the $\mathrm{W}$ mode.

Samples of coronary effluents $(50 \mu \mathrm{L})$ were collected during reperfusion and stored at $4{ }^{\circ} \mathrm{C}$ until further use (within 6 h). Lactate dehydrogenase (LDH) activity was measured using a kit (Promega, Charbonnieres-Les-Bains, France). The accumulated amount of LDH released was obtained by integrating the area under the time-course curve. Results are expressed in arbitrary units (AU) per g of tissue.

\subsection{Vascular reactivity}

\subsubsection{Coronary vasoreactivity test}

The isolated hearts were perfused for $12 \mathrm{~min}$ in the $\mathrm{L}$ mode under constant pressure (55 $\mathrm{mmHg}$ ), then turned to $12 \mathrm{~min}$ of $\mathrm{L}$ mode in constant flow conditions, for which the flow rate was adjusted in order to obtain the same aortic pressure as in the $\mathrm{L}$ preparation $(55 \mathrm{mmHg})$. During this constant flow mode, coronary vasoreactivity was tested by the perfusion of bradykinin (BK $5.10^{-7} \mathrm{~mol} / \mathrm{L}$ ) and sodium nitroprussiate (SNP $10^{-6} \mathrm{~mol} / \mathrm{L}$ ). Coronary reactivity was evaluated through variations in aortic cannula pressure when the hearts were perfused in constant flow conditions. Coronary vascular resistance was calculated according to the formula: Coronary Resistance $(\mathrm{CR})=$ Aortic Pressure (AP) / Coronary Flow (CF). 
2.6.2. Vascular reactivity of the aorta.

Aortic reactivity was measured in freshly excised thoracic aortas as described previously [19]. The functional integrity of arterial rings was tested with $\mathrm{KCl}(60 \mathrm{mmol} / \mathrm{L})$, and the presence or absence of functional endothelium was assessed by acetylcholine (ACh, $1 \mu \mathrm{mol} / \mathrm{L}$ )-induced relaxation of aortic rings preconstricted with phenylephrine $(1 \mu \mathrm{mol} / \mathrm{L})$.

To assess vasoconstrictive responses, the rings were contracted with cumulative additions of phenylephrine $\left(10^{-9}-3.10^{-5} \mathrm{~mol} / \mathrm{L}\right.$ ) or $\mathrm{U} 46619$ (analog of the prostaglandin $\mathrm{PGH} 2,10^{-10}-10^{-6}$ mol/L). To assess vasorelaxing responses, arteries were pre-contracted with phenylephrine $\left(10^{-6} \mathrm{~mol} / \mathrm{L}\right)$, and cumulative concentration-response curves for ACh $\left(10^{-9}-3.10^{-5} \mathrm{~mol} / \mathrm{L}\right)$ and SNP $\left(10^{-10}-10^{-5} \mathrm{~mol} / \mathrm{L}\right)$ were constructed. Relaxation values were expressed as percentage decreases in phenylephrine-induced vasoconstriction.

\subsection{Ventricular remodeling}

\subsubsection{Collagen content}

Heart ventricles were fixed in $4 \%$ paraformaldehyde. Histological analysis was used to determine the development of cardiac fibrosis by staining of paraffin sections for total collagen with picrosirius red. This was quantified using computerized image analysis (ImageJ-1.43 software, Wayne-Rasband NIH, MA, USA), which was manually set to a detection level threshold. Ten fields were randomly chosen from each section of left ventricle, analyzed by the same blinded experimenter, and the mean intensity was calculated. The percentage area was determined by calculating the positive stained area as a percentage of the total image area. 
2.7.2. Matrix metallo-proteinase-2 (MMP-2) expression and activity

Total RNA was extracted from the ventricles with Trizol reagent (Invitrogen, Cergy Pontoise, France). mRNA $(1 \mu \mathrm{g})$ was reverse transcribed with MMLV reverse transcriptase (Invitrogen, id.) using random hexamers (Invitrogen, id.) according to the manufacturer's instructions. Real-time quantitative polymerase chain reaction (RT-PCR) was performed with $2 \mu \mathrm{L}$ of cDNA using the SYBR-Green PCR Master-Mix (Applied Biosystems) and both sense and antisense primers $(5 \mu \mathrm{mol} / \mathrm{L})$ in a final volume of $20 \mu \mathrm{L}$, in an 7500 -Fast-Real-Time PCR system (Applied Biosystems). The primers used for the amplification of rat MMP-2 were: forward 5'-GAGAAAAGCGCAGCGGAGTGACG-3', and reverse 5'TTCCCCCGCAAGCCCAAGTG-3'. Target gene expression was normalized against GAPDH gene expression.

Proteins were extracted from frozen heart tissue in lysis buffer containing $250 \mathrm{mmol} / \mathrm{L}$ Tris$\mathrm{HCl}$ (pH 7.4), $200 \mathrm{mmol} / \mathrm{L} \mathrm{NaCl}$, Nonidet-P40 1\%. Protein concentrations were determined by the Lowry method. Samples were mixed with SDS buffer without a reducing agent and 30 $\mu \mathrm{g}$ of proteins were loaded onto a $10 \%$ SDS-polyacrylamide gel containing $0.1 \%$ gelatin. After electrophoresis, the gels were incubated with 2.5\% Triton X-100 for 2 times $30 \mathrm{~min}$, and then incubated overnight at $37^{\circ} \mathrm{C}$ with buffer $(50 \mathrm{mmol} / \mathrm{L}$ Tris- $\mathrm{HCl}, \mathrm{pH} 8.0,150 \mathrm{mmol} / \mathrm{L}$ $\mathrm{NaCl}$, and $10 \mathrm{mmol} / \mathrm{L} \mathrm{CaCl}_{2}$ and $0.02 \%$ Triton $\mathrm{X}-100, \mathrm{pH}$ 7.4). The gels were stained with $0.1 \%$ Coomassie-brilliant-blue, and gelatinolytic activity was revealed as clear bands against a blue-stained background. Digestion bands were quantitated by an image analyzer system (Image-J-1.43 software, Wayne-Rasband-NIH, MA, USA). 


\subsection{Statistical analysis}

The results are expressed as mean values \pm SEM. The statistical significance of differences between two means was determined by a Student's $t$-test. For weight gain and food consumption, a repeat ANOVA was performed to investigate differences between the two groups.

\section{Results}

\subsection{Body weight and food consumption}

Weight gain was significantly greater in overfed pups during the suckling period (Figure 1A). At weaning (day 24), OF rats showed a 50\% increase in body weight; the increase in body weight persisted with maturation, but was less marked (10\%) (Figure 1B). This increase in body weight was associated with a significantly greater food intake $(+15 \%)$ in OF than in NF rats (Figure $1 \mathrm{C}$ and D). Heart weight of 7-months old $\mathrm{OF}$ rats was also $10 \%$ higher than that of NF (1.29 \pm 0.03 vs. $1.15 \pm 0.05)$ but the heart weight/body weight ratio, a global marker of cardiac hypertrophy, was identical in the two groups.

\subsection{Biochemical parameters}

As shown in Table 1, we observed a 10\% increase in fasting blood glucose in 6-month-old OF rats. No significant difference was observed between OF and NF rats concerning cholesterol and triglyceride levels. However, plasma levels of fasting insulin and leptin were significantly 
greater in OF rats than in NF rats $(\mathrm{p}<0.05)$. In contrast, adiponectin levels were significantly lower in OF rats.

\section{3. $\quad$ Oxidative stress measurements in plasma and tissues}

We observed significantly higher plasma levels of hydroperoxide (Figure 2A) and lower levels of plasma vitamin C (Figure 2B) in the OF group than in the NF group.

In heart ventricular tissue, SOD total activity was significantly higher in the OF group than in the NF group (figure 2C). However, cardiac catalase activities in the OF $(84.7 \pm 2.7 \mathrm{IU} / \mathrm{mg}$ protein) and NF (84.5 $\pm 2.3 \mathrm{IU} / \mathrm{mg}$ protein) rats were not different.

NADPH oxidase activity in heart tissue homogenates (OF: $95.2 \pm 15.6$; NF: $115.6 \pm 8.2$ RLU/mg protein) and in thoracic aortas (OF: $1778 \pm 193$; NF: $1738 \pm 141$ RLU/mg dry weight) were not significantly different either.

\subsection{Heart's susceptibility to ischemia/reperfusion injury}

In baseline perfusion conditions, there was no difference between OF and NF rats in all of the cardiac parameters measured (Table 2). After 30 minutes of ischemia, reperfusing the myocardium led to a progressive but incomplete recovery of the heart's circulating and contractile activity. After $12 \mathrm{~min}$ of reperfusion in the L-mode and $30 \mathrm{~min}$ in the $\mathrm{W}$-mode, the recovery of coronary flow was approximately $65 \%$ of the pre-ischemic values, while recovery of LVDP, $+\mathrm{dP} / \mathrm{dt}$ and $-\mathrm{dP} / \mathrm{dt}$ were $38 \%, 33 \%$ and $38 \%$ respectively. For these parameters, hearts from NF rats and OF rats did not differ significantly. However, the recovery of cardiac output was significantly lower $(38 \%$ vs. $65 \%, \mathrm{p}<0.05)$ in OF than in NF (Figure $3 \mathrm{~A})$. In 
addition, the total amount of LDH, a marker of cell injury, released in the coronary effluent during the period of reperfusion, was found to be significantly higher in post-ischemic OF hearts than in NF hearts (Figure 3B).

\subsection{Vascular reactivity}

In isolated hearts perfused in constant flow conditions, the perfusion of BK or SNP in the coronary vasculature led to a drop in aortic perfusion pressure consecutive to a decrease in coronary vascular resistance (Figure 4). There was no difference between NF hearts and OF hearts for the coronary endothelium-dependent and independent response.

In isolated aortic tissue, the addition of increasing concentrations of phenylephrine or U46619, led to a gradual vasoconstrictive response, for which the aorta of NF or OF rats did not differ (Figure 5A and B). The addition of increasing concentrations of ACh or of SNP gradually relaxed preconstricted arteries, showing the integrity of both endothelial and smooth muscle responses (Figure 5A and B). No differences between NF and OF groups were observed concerning their aortic vasoreactivity (Figure 5C and D).

\subsection{Ventricular remodeling}

Histological studies showed a higher collagen density (+54\%) in the left and right ventricles of adult OF rat hearts (Figure 6A and 6B). The analysis of MMP-2 expression by quantitative RT-PCR and activity by gelatin zymography in whole ventricles (left and right) showed an increase in both MMP-2 expression and activity in OF rat heart ventricular tissue (Figure 6C and D). 


\section{Discussion}

Earlier studies suggested that obesity and overweight were important factors in the development of diabetes and in the aggravation of cardiovascular risk in adulthood.

The experimental model of postnatal OF (overfeeding) induced by reducing litter size is a newly described model of early nutritional disturbances, due to the greater availability of breast milk in the immediate postnatal period. These disturbances can lead to the development of immediate and long-term modifications not only in body weight and food intake, but also in several biochemical and metabolic abnormalities [4, 20, 21]. In our study, we found that POF induced a tremendous increase in body weight at weaning $(+50 \%)$; the increase in body weight persisted with maturation, though at a lower level $(+10 \%)$, along with a permanent increase in food consumption $(+15 \%)$. Additionally, we did not observe any changes in heart weight/body weight ratio in OF adult rats. These observations are consistent with earlier studies [22], with some differences that could be due to the number of pups per mother, strains and the composition of the standard diet. Some authors showed that the increase in body weight observed in OF rats was mainly due to an accumulation of visceral adipose tissue $[5,7,23]$.

In fact, postnatal overfeeding leads to the increased inhibition by neuropeptide Y (NPY) of hypothalamic ventro-median nucleus (VMN) neurons, which are involved in satiety regulation [24]. This could explain the hyperphagia observed in OF rats in our study. Hyperphagia in adulthood in our study was accompanied by an increase in plasma insulin and leptin, a result that confirms those of Plageman and others [4, 7, 9]. Leptin is an adipokine known to reduce food intake and increase energy expenditure, and circulating levels of leptin are directly proportional to whole body adipose mass. Though OF rats have increased circulating levels of leptin, recent studies suggest they have central leptin resistance, due to 
lower type-b leptin receptor [9, 25], lower JAK2 and STAT3 and higher SOCS3 [26] expression in the hypothalamus. Previous studies have shown that malformations of hypothalamic nuclei are induced by hyperinsulinemia during the neonatal period [27]. In fact, hyperinsulinemia and hyperleptinemia start in the earliest stages of life in OF pups, and lead to permanent insulin resistance at both the hypothalamic [28] and peripheral [29] levels.

Alterations in certain biochemical parameters, such as increased fasting glucose and an impaired glucose/insulin ratio, were observed in OF rats. This elevation of fasting glucose by postnatal OF is sometimes observed at weaning [7, 26] and later in life $[4,7]$, but this change does not seem to be constantly present in overfed rats. On the contrary, a drop in the glucose/insulin ratio is frequently reported $[7,8,23,30]$, as is glucose intolerance shown by modifications in oral or intra-peritoneal glucose tolerance tests $[4,5,7,8,23,26]$, corresponding to a situation of pre-diabetes. Concerning plasma lipids, we found no modifications in fasting triglycerides and cholesterol levels in OF rats. Certain studies have shown not only an increase in plasma triglycerides and cholesterol in OF pups at weaning [31] and later [7], but also increases in circulating free fatty acid (FFA) [7, 8]. Some authors have shown that hyperinsulinemia may stimulate the storage and accumulation of FFA in adipose tissue $[32,33]$, but the experimental conditions of our study did not allow us to confirm this hypothesis.

Given that OF rats had increased adipose mass [5, 7, 23], we also assessed the plasma levels of two adipokines, leptin and adiponectin, at 180 days and found an increase in leptin and a decrease in adiponectin in OF rats. The increase in leptin levels in OF animals is constantly reported in the literature $[6,7,9,23,26,29,34]$, and can be explained by the fact that leptin levels are related to the amount of fat mass. Concerning adiponectin, our results corroborate those obtained by Boullu-Ciocca and collaborators [8] at 150 days, but other studies showed no difference at 4 and 6 months between OF and NF groups [6, 26]. Adiponectin production 
is inversely proportional to whole body adipose mass, and experimental studies suggest that it modulates the action of insulin and thus improves insulin sensitivity in peripheral tissues [35] and induces general cardioprotective effects [36].

Obesity and overweight are associated with increased oxidative stress not only in the bloodstream, but also in myocardial tissue $[37,38]$. However, to date, no other study has explored the impact of $\mathrm{OF}$ on oxidative stress markers such as peroxidation products, tissue activity of enzymes such as NADPH oxidases or vitamin or enzyme-related antioxidant defenses. In our study, we evaluated circulating levels of hydroperoxides and vitamin $\mathrm{C}$ and observed an increase in hydroperoxides and a decrease in vitamin $\mathrm{C}$ levels indicating increased circulating oxidative stress in OF rats. Unlike humans, rats synthetize their own vitamin $\mathrm{C}$ in the liver, but they can also ingest it in their food. However, intestinal transporters of ascorbate or dehydroascorbate are not very abundant in rodents except in gulunolactone oxidase-deficient strains $[39,40]$ and the composition of the standard diet we have used in our study does not mention the presence of vitamin $\mathrm{C}$. Therefore, the decrease in vitamin $\mathrm{C}$ could be related to a higher depletion of this hydro-soluble antioxidant vitamin due to increased circulating oxidative stress, evidenced by higher peroxidation markers. However, we cannot exclude the possibility of lower hepatic synthesis of vitamin C. This increase in oxidative stress cannot be explained by increased NADPH oxidase activity in vessels or tissues, since in our study it was not modified in OF aortas or hearts. In the context of overweight, other factors, such as a higher rate of mitochondrial oxidative activity, might explain an increase in oxidative stress. Paradoxically, we also observed a significant increase in SOD activity in heart tissue homogenates, which could reflect an adaptive response to oxidative stress. In fact, some studies have demonstrated an association between obesity and increased myocardial oxidative stress [38]. Concerning the adaptive response, we previously showed in rats with 
major vitamin $\mathrm{C}$ deficiency, an up-regulation of several antioxidant and protective pathways such as CuZn and MnSOD [39].

Given the metabolic alterations and increased oxidative stress induced by postnatal overfeeding, we addressed the consequences of overfeeding on cardiovascular parameters. We first examined the recovery of pre-ischemic developed pressure, contractility and relaxation after $\mathrm{I} / \mathrm{R}$ injury, and then aortic and coronary vasoreactivity. We found that postnatal-OF induced higher susceptibility of the heart to ischemia-induced injury, as shown by a lower recovery of pre-ischemic cardiac output and an increase in cardiac LDH release and activity, indicating more severe cell damage. However in our study, we found no significant differences in basal vascular parameters such as aortic and coronary vasoreactivity, or in levels of systemic arterial pressure (data not shown). Nevertheless, some studies have shown that a high-fat diet induces dysfunctions in endothelium-dependent vasorelaxation [41] which can be restored by dietary antioxidants $[41,42]$. However, since rodents are known to have low plasma LDL and are not prone to developing atherosclerosis, wild-type rats may not be the ideal model to study the vascular consequences of moderate overweight, and future research should be conducted in genetically-modified models to overcome this problem. Therefore, two conclusions may be drawn from these contrasting results. In our model, the OF-induced metabolic and hormonal alterations were not severe enough to induce modifications of vascular reactivity, despite the increase in circulating markers of oxidative stress. However, in a stressful condition such as I/R injury, which generates a massive release of reactive oxygen species [43, 44], the metabolic alteration induced by OF renders the myocardium more susceptible to injury. In addition, it is unlikely that this higher susceptibility is due to the restricted recovery of coronary perfusion (not modified in basal and post-ischemic conditions), and is therefore more probably related to impaired responses 
from the cardiomyocytes themselves. In keeping with this hypothesis, previous studies suggested that overfeeding in the neonatal period can induce left ventricular hypertrophy at 21 days [31] and increased cardiac fibrosis in 16-week-old adult hearts [34].

We therefore explored the possibility of ventricular remodeling and found both an increase in collagen content and an increase in MMP-2 expression and activity in the ventricles of OF rats, showing an alteration of the architectural organization of hearts from moderately overweight 6-months-old OF rats. Several environmental factors such as oxidative stress or increased leptin levels might explain the occurrence of this remodeling phenomenon. Indeed, studies have highlighted the role of leptin and insulin in the elongation of cardiac myocytes [45], ventricular hypertrophy [46, 47], and heart failure [48]. The accumulation of fibrous tissue, mainly type I and III collagen, is a major contributing factor in heart failure, and certain authors showed, in an angiotensin II model of non-hypertrophic remodeling [49], that rat hearts with accumulations of collagen similar to those observed in our study were more prone to ischemia-reperfusion injury. In fact, collagen accumulation could lead to increased stiffening of the myocardium, thus impairing diastolic filling of the ventricle (although we found no changes in ventricular function using in vivo echocardiography), which may hamper the recovery of cardiac output after ischemia.

\section{Conclusion}

To conclude, our study highlights OF-induced increases in circulating markers of oxidative stress, while showing for the first time that the myocardium of moderately-overweight adult OF rats is more prone to ischemia-reperfusion injury, which may be explained, at least in part, by ventricular remodeling. Indeed, our study supports the well-known hypothesis that 
nutritional changes occurring in the neonatal period may induce epigenetic modifications that affect gene expression and thus alter metabolic features in adulthood [50]. From a clinical point of view, this genetic imprinting encountered in either low birth weight [51] or, on the contrary, postnatal overweight infants in a context of maternal diabetes, is now recognized as risk factor for cardiovascular disease in overweight individuals $[52,53]$. These results suggest that the nutritional state in the immediate postnatal period should be taken into account since it may have an impact on cardiovascular risk in adulthood, even in moderately overweight individuals. 


\section{ACKNOWLEDGMENTS}

The authors thank Mr. P. Bastable for English revision of the manuscript, the French Ministry of Research and the Regional Council of Burgundy for funding and $\mathrm{PhD}$ granting, and Eve Rigal for technical assistance. 


\section{References}

[1] M. Zeller, P.G. Steg, J. Ravisy, Y. Laurent, L. Janin-Manificat, I. L'Huillier, J.C. Beer, A. Oudot, G. Rioufol, H. Makki, M. Farnier, L. Rochette, B. Verges, Y. Cottin, Prevalence and impact of metabolic syndrome on hospital outcomes in acute myocardial infarction, Arch Intern Med 165 (2005) $1192-1198$.

[2] M. Zeller, P.G. Steg, J. Ravisy, L. Lorgis, Y. Laurent, P. Sicard, L. Janin-Manificat, J.C. Beer, H. Makki, A.C. Lagrost, L. Rochette, Y. Cottin, Relation between body mass index, waist circumference, and death after acute myocardial infarction, Circulation 118 (2008) 482-490.

[3] K.L. Spalding, E. Arner, P.O. Westermark, S. Bernard, B.A. Buchholz, O. Bergmann, L. Blomqvist, J. Hoffstedt, E. Naslund, T. Britton, H. Concha, M. Hassan, M. Ryden, J. Frisen, P. Arner, Dynamics of fat cell turnover in humans, Nature 453 (2008) 783-787.

[4] A. Plagemann, T. Harder, A. Rake, M. Voits, H. Fink, W. Rohde, G. Dorner, Perinatal elevation of hypothalamic insulin, acquired malformation of hypothalamic galaninergic neurons, and syndrome x-like alterations in adulthood of neonatally overfed rats, Brain Res 836 (1999) 146-155.

[5] L.C. Balonan, H.P. Sheng, Perinatal feedings adversely affect lipogenic activities but not glucose handling in adult rats, Pediatr Res 48 (2000) 668-673.

[6] E. Velkoska, T.J. Cole, M.J. Morris, Early dietary intervention: long-term effects on blood pressure, brain neuropeptide Y, and adiposity markers, Am J Physiol Endocrinol Metab 288 (2005) E1236-1243.

[7] S. Boullu-Ciocca, A. Dutour, V. Guillaume, V. Achard, C. Oliver, M. Grino, Postnatal dietinduced obesity in rats upregulates systemic and adipose tissue glucocorticoid metabolism during development and in adulthood: its relationship with the metabolic syndrome, Diabetes 54 (2005) 197 203.

[8] S. Boullu-Ciocca, V. Achard, V. Tassistro, A. Dutour, M. Grino, Postnatal programming of glucocorticoid metabolism in rats modulates high-fat diet-induced regulation of visceral adipose tissue 
glucocorticoid exposure and sensitivity and adiponectin and proinflammatory adipokines gene expression in adulthood, Diabetes 57 (2008) 669-677.

[9] M. Lopez, L.M. Seoane, S. Tovar, M.C. Garcia, R. Nogueiras, C. Dieguez, R.M. Senaris, A possible role of neuropeptide $\mathrm{Y}$, agouti-related protein and leptin receptor isoforms in hypothalamic programming by perinatal feeding in the rat, Diabetologia 48 (2005) 140-148.

[10] F. Boubred, C. Buffat, J.M. Feuerstein, L. Daniel, M. Tsimaratos, C. Oliver, M. LelievrePegorier, U. Simeoni, Effects of early postnatal hypernutrition on nephron number and long-term renal function and structure in rats, Am J Physiol Renal Physiol 293 (2007) F1944-1949.

[11] A. Galinier, A. Carriere, Y. Fernandez, C. Carpene, M. Andre, S. Caspar-Bauguil, J.P. Thouvenot, B. Periquet, L. Penicaud, L. Casteilla, Adipose tissue proadipogenic redox changes in obesity, J Biol Chem 281 (2006) 12682-12687.

[12] S. Furukawa, T. Fujita, M. Shimabukuro, M. Iwaki, Y. Yamada, Y. Nakajima, O. Nakayama, M. Makishima, M. Matsuda, I. Shimomura, Increased oxidative stress in obesity and its impact on metabolic syndrome, J Clin Invest 114 (2004) 1752-1761.

[13] A. Galinier, A. Carriere, Y. Fernandez, S. Caspar-Bauguil, B. Periquet, A. Periquet, L. Penicaud, L. Casteilla, Site specific changes of redox metabolism in adipose tissue of obese Zucker rats, FEBS Lett 580 (2006) 6391-6398.

[14] F. Tessier, I. Birlouez-Aragon, C. Tjani, J.C. Guilland, Validation of a micromethod for determining oxidized and reduced vitamin $\mathrm{C}$ in plasma by HPLC-fluorescence, Int J Vitam Nutr Res 66 (1996) 166-170.

[15] A. Ecarnot-Laubriet, L. Rochette, C. Vergely, P. Sicard, J.-R. Teyssier, The activation pattern of the antioxidant enzymes in the right ventricle of rat in response to pressure overload is of heart failure type., Heart Dis 5 (2003) 308-312.

[16] F. Dalloz, P. Maingon, Y. Cottin, F. Briot, J.-C. Horiot, L. Rochette, Effects of combined irradiation and doxorubicin treatment on cardiac function and antioxidant defenses in the rat, Free Radic Biol Med 26 (1999) 785-800.

[17] H. Aebi, Catalase in vitro, Methods in Enzymology 105 (1984) 121-126. 
[18] C. Korandji, M. Zeller, J.C. Guilland, B. Collin, B. Lauzier, P. Sicard, L. Duvillard, F. Goirand, D. Moreau, Y. Cottin, L. Rochette, C. Vergely, Time course of asymmetric dimethylarginine (ADMA) and oxidative stress in fructose-hypertensive rats: a model related to metabolic syndrome, Atherosclerosis 214 (2011) 310-315.

[19] R. Debin, B. Lauzier, P. Sicard, S. Delemasure, S. Amoureux, L. Duvillard, C. Vergely, Y. Cottin, L. Rochette, Are Zucker obese rats a useful model for cardiovascular complications in metabolic syndrome? Physical, biochemical and oxidative stress considerations, Fundam Clin Pharmacol 23 (2009) 59-67.

[20] R.A. Waterland, C. Garza, Potential mechanisms of metabolic imprinting that lead to chronic disease, Am J Clin Nutr 69 (1999) 179-197.

[21] S. Sivanandam, A.R. Sinaiko, D.R. Jacobs, Jr., L. Steffen, A. Moran, J. Steinberger, Relation of increase in adiposity to increase in left ventricular mass from childhood to young adulthood, Am $\mathbf{J}$ Cardiol 98 (2006) 411-415.

[22] L. Kappeler, C. De Magalhaes Filho, P. Leneuve, J. Xu, N. Brunel, C. Chatziantoniou, Y. Le Bouc, M. Holzenberger, Early postnatal nutrition determines somatotropic function in mice, Endocrinology 150 (2009) 314-323.

[23] A.C. de Souza Rodrigues Cunha, R.O. Pereira, M.J. Dos Santos Pereira, V. de Melo Soares, M.R. Martins, M. Teixeira Teixeira, E.P. Souza, A.S. Moura, Long-term effects of overfeeding during lactation on insulin secretion - the role of GLUT-2, J Nutr Biochem (2008).

[24] E. Heidel, A. Plagemann, H. Davidowa, Increased response to NPY of hypothalamic VMN neurons in postnatally overfed juvenile rats, Neuroreport 10 (1999) 1827-1831.

[25] S. Rajia, H. Chen, M.J. Morris, Maternal overnutrition impacts offspring adiposity and brain appetite markers-modulation by postweaning diet, J Neuroendocrinol 22 (2010) 905-914.

[26] A.L. Rodrigues, E.G. de Moura, M.C. Passos, I.H. Trevenzoli, E.P. da Conceicao, I.T. Bonono, J.F. Neto, P.C. Lisboa, Postnatal early overfeeding induces hypothalamic higher SOCS3 expression and lower STAT3 activity in adult rats, J Nutr Biochem 22 (2011) 109-117. 
[27] A. Plagemann, T. Harder, U. Janert, A. Rake, F. Rittel, W. Rohde, G. Dorner, Malformations of hypothalamic nuclei in hyperinsulinemic offspring of rats with gestational diabetes, Dev Neurosci $21(1999) 58-67$.

[28] H. Davidowa, A. Plagemann, Insulin resistance of hypothalamic arcuate neurons in neonatally overfed rats, Neuroreport 18 (2007) 521-524.

[29] R.O. Pereira, A.S. Moreira, L. de Carvalho, A.S. Moura, Overfeeding during lactation modulates insulin and leptin signaling cascade in rats' hearts, Regul Pept 136 (2006) 117-121.

[30] A. Plagemann, T. Harder, A. Rake, K. Melchior, W. Rohde, G. Dorner, Increased number of galanin-neurons in the paraventricular hypothalamic nucleus of neonatally overfed weanling rats, Brain Res 818 (1999) 160-163.

[31] A.S. Moreira, M. Teixeira Teixeira, F. da Silveira Osso, R.O. Pereira, G. de Oliveira SilvaJunior, E.P. Garcia de Souza, C.A. Mandarim de Lacerda, A.S. Moura, Left ventricular hypertrophy induced by overnutrition early in life, Nutr Metab Cardiovasc Dis 19 (2009) 805-810.

[32] C. Morisco, G. Lembo, B. Trimarco, Insulin resistance and cardiovascular risk: New insights from molecular and cellular biology, Trends Cardiovasc Med 16 (2006) 183-188.

[33] J. Ilany, P.J. Bilan, S. Kapur, J.S. Caldwell, M.E. Patti, A. Marette, C.R. Kahn, Overexpression of Rad in muscle worsens diet-induced insulin resistance and glucose intolerance and lowers plasma triglyceride level, Proc Natl Acad Sci U S A 103 (2006) 4481-4486.

[34] E. Velkoska, T.J. Cole, R.G. Dean, L.M. Burrell, M.J. Morris, Early undernutrition leads to long-lasting reductions in body weight and adiposity whereas increased intake increases cardiac fibrosis in male rats, J Nutr 138 (2008) 1622-1627.

[35] Y. Matsuzawa, The metabolic syndrome and adipocytokines, FEBS Lett 580 (2006) 29172921.

[36] O. Gualillo, J.R. Gonzalez-Juanatey, F. Lago, The emerging role of adipokines as mediators of cardiovascular function: physiologic and clinical perspectives, Trends Cardiovasc Med 17 (2007) 275283. 
[37] D.W. Laight, K.M. Desai, N.K. Gopaul, E.E. Anggard, M.J. Carrier, F2-isoprostane evidence of oxidant stress in the insulin resistant, obese Zucker rat: effects of vitamin E, Eur J Pharmacol 377 (1999) 89-92.

[38] H.K. Vincent, S.K. Powers, D.J. Stewart, R.A. Shanely, H. Demirel, H. Naito, Obesity is associated with increased myocardial oxidative stress, Int J Obes Relat Metab Disord 23 (1999) 67-74. [39] C. Vergely, C. Perrin, A. Laubriet, A. Oudot, M. Zeller, J.-C. Guilland, L. Rochette, Postischemic recovery and oxidative stress status of vitamin C-deficient rat hearts, Cardiovasc Res 51 (2001) 89-99.

[40] C. Vergely, F. Goirand, A. Ecarnot-Laubriet, C. Renard, D. Moreau, J.C. Guilland, M. Dumas, L. Rochette, Vitamin C deficiency exerts paradoxical cardiovascular effects in Osteogenic Disorder Shionogi (ODS) rats, Journal of Nutrition 134 (2004) 729-735.

[41] J. Sato, T. O'Brien, Z.S. Katusic, A. Fu, J. Nygren, R. Singh, K.S. Nair, Dietary antioxidants preserve endothelium dependent vasorelaxation in overfed rats, Atherosclerosis 161 (2002) 327-333.

[42] J.F. Keaney, Jr., J.M. Gaziano, A. Xu, B. Frei, J. Curran-Celentano, G.T. Shwaery, J. Loscalzo, J.A. Vita, Dietary antioxidants preserve endothelium-dependent vessel relaxation in cholesterol-fed rabbits, Proc Natl Acad Sci U S A 90 (1993) 11880-11884.

[43] C. Vergely, V. Maupoil, M. Benderitter, L. Rochette, Influence of the severity of myocardial ischemia on the intensity of ascorbyl free radical release and on post-ischemic recovery during reperfusion, Free Radic Biol Med 24 (1998) 470-479.

[44] C. Vergely, A. Tabard, V. Maupoil, L. Rochette, Isolated perfused rat hearts release secondary free radicals during ischemia reperfusion injury. Cardiovascular effect of the spin trap alpha-phenyl $\mathrm{N}$ tert-butylnitrone, Free Radic Res 35 (2001) 475-489.

[45] Y. Abe, K. Ono, T. Kawamura, H. Wada, T. Kita, A. Shimatsu, K. Hasegawa, Leptin induces elongation of cardiac myocytes and causes eccentric left ventricular dilatation with compensation, Am J Physiol Heart Circ Physiol 292 (2007) H2387-2396.

[46] L. Perego, P. Pizzocri, D. Corradi, F. Maisano, M. Paganelli, P. Fiorina, M. Barbieri, A. Morabito, G. Paolisso, F. Folli, A.E. Pontiroli, Circulating leptin correlates with left ventricular mass 
in morbid (grade III) obesity before and after weight loss induced by bariatric surgery: a potential role for leptin in mediating human left ventricular hypertrophy, J Clin Endocrinol Metab 90 (2005) 40874093.

[47] S. Fredersdorf, C. Thumann, C. Ulucan, D.P. Griese, A. Luchner, G.A. Riegger, E.P. Kromer, J. Weil, Myocardial hypertrophy and enhanced left ventricular contractility in Zucker diabetic fatty rats, Cardiovasc Pathol 13 (2004) 11-19.

[48] P.C. Schulze, J. Kratzsch, A. Linke, N. Schoene, V. Adams, S. Gielen, S. Erbs, S. MoebiusWinkler, G. Schuler, Elevated serum levels of leptin and soluble leptin receptor in patients with advanced chronic heart failure, Eur J Heart Fail 5 (2003) 33-40.

[49] M.B. Aljabri, T. Lund, A.C. Hoper, T.V. Andreasen, S. Al-Saad, S. Lindal, K. Ytrehus, Gene expression, function and ischemia tolerance in male and female rat hearts after sub-toxic levels of angiotensin II, Cardiovasc Toxicol 11 (2011) 38-47.

[50] K.A. Lillycrop, G.C. Burdge, Epigenetic changes in early life and future risk of obesity, Int J Obes (Lond) 35 (2011) 72-83.

[51] K. Rajaleid, I. Janszky, J. Hallqvist, Small birth size, adult overweight, and risk of acute myocardial infraction, Epidemiology 22 (2011) 138-147.

[52] J.L. Baker, L.W. Olsen, T.I. Sorensen, Childhood body-mass index and the risk of coronary heart disease in adulthood, N Engl J Med 357 (2007) 2329-2337.

[53] D.A. Lawlor, L. Benfield, J. Logue, K. Tilling, L.D. Howe, A. Fraser, L. Cherry, P. Watt, A.R. Ness, G. Davey Smith, N. Sattar, Association between general and central adiposity in childhood, and change in these, with cardiovascular risk factors in adolescence: prospective cohort study, BMJ 341 (2010) c6224. 


\section{Legends to figures:}

Figure 1: Increase in body weight and food intake during life in NF and OF rats.

Graph B shows the percentage of body weight increase in OF rats as compared to that in NF rats. Number of animals per group $=10$.

*, $\mathrm{P}<0.05$ was considered significant (one-way ANOVA).

Figure 2: Oxidative stress indexes in plasma and heart tissue.

A: plasma hydroperoxides. B: plasma vitamin C concentration. C: cardiac SOD activity.

D: cardiac catalase activity

Figure 3: Myocardial contractility parameters and tissue injury after ischemia. A: recovery of pre-ischemic cardiac output, B: LDH activity in coronary effluent, a marker of the extent of necrosis. Hearts were subjected to $30 \mathrm{~min}$ of ischemia $\left(37^{\circ} \mathrm{C}\right)$ and $45 \mathrm{~min}$ of reperfusion.

Figure 4: Coronary vasoreactivity as measured by variations in coronary resistance in NF and OF isolated hearts: perfused in the presence of endothelium-dependent (BK 5.10 ${ }^{-7}$ $\mathrm{mol} / \mathrm{L}$ ) and endothelium-independent (SNP $\left.10^{-6} \mathrm{~mol} / \mathrm{L}\right)$ vasodilators. Variations in coronary resistance are expressed in percentages.

Figure 5: Aortic reactivity of isolated thoracic aortas of NF or OF rats: subjected to different concentrations of vasoconstrictors and vasodilators. A: Phenylephrine, B: U46619 (analog of the prostaglandin $\mathrm{PGH}_{2}$ ), C: Acetylcholine, D: Sodium nitroprussiate (SNP).

Figure 6: Ventricular remodeling of hearts from NF or OF rats: A: representative pircosirius collagen staining of ventricular tissue. B: collagen density (\% of area), C: MMP-2 mRNA expression (quantitative RT-PCR) and D: activity (gelatin zymography). 
Table 1: Metabolic parameters of NF and OF rats groups. Fasting blood glucose was assayed by glucometry; cholesterol and triglycerides were assayed using colorimetric methods and plasma insulin, leptin and adiponectin were estimated using ELISA. P was calculated by Student's $t$-test.

NF

$\mathrm{OF}$

Fasting glucose $(\mathrm{mmol} / \mathrm{L})$

$7.49 \pm 0.32$

$8.30 \pm 0.37 *$

Cholesterol $(\mathrm{g} / \mathrm{L})$

$0.80 \pm 0.03$

$0.88 \pm 0.10$

Triglycerides (g/L)

$0.75 \pm 0.08$

$0.90 \pm 0.18$

Insulin (mIU/L)

$40.2 \pm 8.8$

$67.0 \pm 7.9 *$

Leptin (ng/dL)

$4.03 \pm 0.48$

$5.84 \pm 0.48 *$

Adiponectin $(\mu \mathrm{g} / \mathrm{mL})$

$7.07 \pm 0.55$

$5.12 \pm 0.57 *$

*, $P<0.05$, NF vs. OF group. 
Table 2: Pre-ischemic isolated heart parameters of normally fed (NF) or postnatal overfed (OF) 7 months's old rats. Parameters were recorded after $12 \mathrm{~min}$ in the Langendorff mode, (L 12) and after 12 min in the working mode (W12). P was calculated by Student's $t$-test.

\begin{tabular}{ccccc}
\hline & \multicolumn{2}{c}{ NF } & \multicolumn{2}{c}{ OF } \\
& L 12 & W 12 & L 12 & W 12 \\
\hline Coronary output (ml/min/g) & $13.0 \pm 0.5$ & $12.1 \pm 1.0$ & $13.2 \pm 0.7$ & $15.3 \pm 2.2$ \\
Cardiac output (ml/min/g) & $13.0 \pm 0.5$ & $14.57 \pm 1.94$ & $13.24 \pm 0.67$ & $16.77 \pm 2.52$ \\
LV developed pressure (mmHg) & $66.9 \pm 4.1$ & $76.8 \pm 6.2$ & $66.8 \pm 2.3$ & $81.5 \pm 6.3$ \\
$+\mathrm{dP} / \mathrm{dt}(\mathrm{mmHg})$ & $1796 \pm 97$ & $1886 \pm 169$ & $1785 \pm 35$ & $1988 \pm 150$ \\
-dP/dt (mmHg) & $-1163 \pm 77$ & $-1252 \pm 142$ & $-1152 \pm 42$ & $-1366 \pm 139$ \\
\hline
\end{tabular}

